\title{
Conde da Barca, um Português que foi dos Pioneiros na Educação Química no Brasil
}

\author{
A T T ICO INÁCIO C HASSOT*
}

Este textol busca destacar a contribuição do Conde da Barca provavelmente um dos pioneiros da Educação Química brasileira e para tanto se faz uma breve contextualização da Educação no Brasil (Chassot 1994b) na virada do século XVIII para o XIX. As fontes para elaboração desta contextualização foram especialmente documentos oficiais ${ }^{2}$ pois para a época que aqui contempla não há muitas outras informaçōes disponíveis.

Uma marca da educação desta época que permanecerá forte no Brasil Império e também no Brasil República é o caráter centralizador das decisões Compulsando, por exemplo decisões que constam em um alvará de El-Rei, de 6 de Novembro de 1772. (PM-02:26) chega ser surpreendente inúmeros detalhes que o Monarca avoca a si Consta, por exemplo, a subordinação dos estudos em todo o reino e colonias de ultramar a mesas examinadoras em Lisboa, ou ainda a recomendacão de que os mestres que ensinarem a escrever corretamente e as quatro espécies de aritmética simples, ensinem também o catecismo e as regras de civilidade, mas que isto seja feito particularmente dentro das próprias casas. Esta centralização ainda acontecia 113 anos depois, como vemos em uma instrução geral de 1885 , onde se dizia que "nenhum livro, mapa ou objeto de enslno será adotado nas escolas públicas sem a prévia aprovação do Ministro do Império, ouvido o Conselho diretor, que dará parecer fundamentado. (...) Os professores que infringirem disposição deste decreto incorrerão na pena de multa (PM-03 532) Destas determinações para a Educação, uma ainda, para a Colônia e outra já para o ocaso do Império, é fácil inferir quanto qualquer idéia que buscasse responder a exigências de novas propostas eram impedidas de circular.

Em 1786, após a expulsão dos jesuítas ocorrida em 1759, o vice-rei Luiz de Vasconcelos assinalava em documento oficial que "era lamentável o estado das escolas de primeiras letras em todas as capitanias do Brasil: poucas existiam e estas eram exercidas por homens ignorantes." Para exemplificar a natureza do currículo da época, em 1793 foram criadas, pelo vice-rei conde de Rezende, aulas de filosofia, retórica grego, três de latim e duas de primeiras letras. (PM-02:31).

Há três documentos "históricos" em Portugal, na França e no Brasil que, acredito, são definidores do ensino de Química no Brasil i) As normas do Curso filosófico contidas no Estatuto da Universidade de Coimbra (1772), que estão transliteradas e comentadas em Chassot (1994b) ii) Sobre a maneira de ensinar Química de Lavoisier (escrito entre 1790 e 1793) 3 que mesmo inédito quase 200 anos pode ser visto como presente no Traité publicado em 1789 (Chassot: 1993: 1994a) - e iii) as Diretrizes para a cadeira de Química da Bahia do Conde da Barca (1817) aqui parcialmente transcritas e comentadas

O primeiro decreto que refere oficialmente o ensino de Química no Brasil é de 6 de Julho de 1810 e cria uma cadeira de Química, na Real Academia Militar. Há uma Carta de Lei de 4 de Dezembro de 1810 que disciplilna (na mais exata acepção do termo) o ensino. Sobre a docência de Química, nesta Real Academia Militar, há a seguinte informação:

No quinto ano haverá dois lentes $\mathrm{O}$ primeiro ensinará tática e estratégia: o segundo ensinará Química. dará todos os métodos para o conhecimento das minas, servindo-se das obras de Lavoisier. Vandequelin Jouveroi ${ }^{4}$, Lagrange e Chaptal para formar seu compêndio, onde fará toda sua aplicação às artes e a utilidade que dela derivam (PM-02:51)

Este texto nos permite inferir um ensino dedicado a aspectos utilitários. Também se pode ver a quase exclusiva influência francesa, na literatura química de então. As recomendações para a mesma Real Academia Militar dizem que o ensino da Química deve tratar dos métodos docimásticos ${ }^{5}$ para o conhecimento das minas, o que traduz uma preocupação com o aproveitamento das riquezas naturais e também com o quanto a ciência poderia concorrer para tal.
Há um outro decreto real de 25 de Janeiro de 1812, que é histórico para o ensino de Química:

Neste decreto aparece claramente os resultados do governo real estar no Brasil e aqui se vai buscar investigar, através da Química o que se produz nos amplos domínios de alémmares e também há, ainda, a orientação exclusivamente de uma Química Analítica, pois só alguns anos depois a Química buscará fazer sínteses. A criação da Cadeira de Química na Bahia, em Janeiro de 1817 é feita por uma carta real que assim inicia:

Conde de Arcos, governador e capitão general da Capitania da Bahia Eu ElRei vos envio muito saudar, como aquele, que amo. Sendo indispensável não so para o progresso dos estudos da medicina, cirurgia e agricultura, que tenho mandado estabelecer nessa cidade, mas também para o perfeito conhecimento dos muitos e preciosos produtos com que a natureza enriqueceu este reino do Brasil, que se ensinem os princípios práticos da Química e seus diferentes ramos e aplicados às artes e à farmácia: hei por bem crear nessa cidade uma cadeira de Química regulada provisoriamente pelas instruções assinadas pelo conde da Barca, sendo incumbido do ensino das matérias que the são próprias o Dr. Sebastião Navarro de Andrade que sou servido nomear lente da dita cadeira com o ordenado anual de $600 \$ 000$ pagos, a quarteis como os mais professores do subsídio literário dessa Capitania, conservando as honras dos lentes da Universidade de Coimbra e pensão que recebe pela mesma Universidade. (PM-02:63)

A carta prossegue, mostrando a estima de D João Vl pela ciência, com recomendações reais muito centralizadoras para terminar ordenando que ao fim de cada ano letivo façais subir a minha real presença (...) uma circunstanciada conta do resultado de todos os cursos científicos e práticos de agricultura química, medicina e cirurgia que eu tenho aí creado com informação competente sobre a conduta, assiduldade e préstimo de cada um dos lentes, para que com cabal conhecimento de todas as particularidades eu haja de dar as ulte- 
riores providências que me pareçam convenientes.

A esta carta seguem-se extensas instruções palacianas de Antônio de Araújo e Azevedo, o Conde da Barca, um ilustrado colaborador do Rei, que era um entusiasta da Química, e nas determinações que expede, pode se perceber não só o seu apreço por esta ciência, como também as recomendações objetivas para o seu ensino, (e há indicações de que as mesmas cedo foram esquecidas) muito voltado a algumas das posturas que hoje se recomenda para fazer educação através da Química.

Antônio de Araújo e Azevedo (Ponte de Lima, Portugal, 1754 - Rio de Janeiro, Brasil 1817) Estudou Filosofia em Coimbra, e no Porto, Matemática e História. Ministro e embaixador junto à corte de Haia negociou e assinou o tratado de paz com a França, em 1797, que não tendo sido ratificado, levou Araújo e Azevedo ao cárcere por ordem do diretório, sendo libertado quatro meses depois. Na Alemanha onde esteve como diplomata, dedicou-se ao estudo da Ciência e das Letras. Em 1801 foi transferido para a embaixada de São Petersburgo, onde ficou três anos. Foi Ministro dos Estrangeiros e da Guerra em 1804, e dois anos mais tarde assumiu também o Ministério do Reino. Foi um dos maiores partidários da mudança da Corte para o Rio de Janeiro. Embarcou com a Família Real para o Brasil, a bordo do Medusa, quando trouxe sua coleção de livros (depois incorporada na $\mathrm{Bi}$ blioteca Nacional), uma tipografia completa (a primeira regular a existir no Brasil), uma coleção mineralógica e aparelhagem para o estudo da Química. No Brasil dedicou-se a trabalhos científicos. Cultivou mais de 1.500 espécies botânicas, catalogando-as com o nome de Hortus Araujensis. Instalou em sua casa um alambique de tipo escocês e encorajou o fabrico da cerâmica. Incentivou o cultivo do chá tendo mandado vir chineses para cuidar deste cultivar. Em 1814 voltou ao Ministério, ocupando a pasta da Marinha, chegando a ocupar todas as pastas ministeriais, um pouco antes de morrer. Fundou a Imprensa Régia e a Academia de Belas-Artes em 1815, para a qual contratou professores franceses de grande destaque. Em 27 de Dezembro de 1815 recebeu o título de primeiro Conde da Barca. A correspondência do Conde da Barca é considerada de grande interesse histórico científico e político.

Acredito que o Conde da Barca, pode ser considerado como um dos pioneiros da Educação Química brasileira. Das suas instruções não só podemos fazer inferências sobre a situação das publicações químicas em língua portuguesa, como também de valiosas sugestões didáticas para fazer um ensino de Química muito ligado a realidade Vale recordar que ainda não se passara 30 anos da publicação do Traité. É importante conhecer alguns trechos para ver as orientações que o Conde da Barca queria ver imprimidas ao ensino da novel ciência:

O lente da cadeira de Química ensinará a teoria química em geral por um compêndio de sua escolha, enquanto ele não compuser um próprio na língua portuguesa que contenha com conveniente precisão e clareza todas as noções que deve ensinar a seus discípulos. E achando-se traduzida na lingua vulgar a filosofia de Faurevoy, ${ }^{6}$ bom será que, enquanto ordena o seu compêndio use dela para ser mais geral este estudo, fazendo-lhe os adiantamentos que the forem necessários. (...) Dadas as lições gerais da Química, passará as aplicações desta interessante ciência às diferentes artes e ramos da indústria. (...) Fará todas as experiências e análises que forem necessárias, procurando dar aos seus discípulos toda a agilidade e perícia na prática de operações químicas, tendo sempre em vista nas suas lições teóricas e práticas tudo quanto for relativo à farmácia, agricultura, tinturaria, manufatura do açúcar e a extração das substâncias salinas do que se possam colher utilidade, mas também dos óleos, betumes, resinas e gomas. (...) Dará lições práticas de docimástica, e explicará as dificuldades de construcōes dos fornos, tendo particular atenção ao trabalho das minas de ferro e de outros metais, de que ainda abunda o reino do Brasil, para que possam ser utilmente aproveitados. (...) No tempo das férias observará com seus discípulos os terrenos vizinhos da cidade da Bahia para lhes explicar suas formações e ao mesmo tempo colher os produtos mineralógicos que encontrar e achar dignos de observação para servirem as suas lições, e serem guardados no Gabinete de mineralogia que se deve formar, sendo para esse fim convidados todos os que acharem algum fóssil, a fazer entrega dele ao dito Gabinete, pagando-se o seu justo valor, os que exigirem a custa da real fazenda e pela folha de despesa do Laboratório químico, que o Governador e Capitão General fará construir com a conveniente economia, entendendo-se com o lente (...) Pela folha das despesas do Laboratório químico e Gabinete mineralógico serão pagas as despesas que se fizerem com a compra de instrumentos para estas viagens montanísticas bem como a compra de vasos, aparelhos, fornos e tudo quanto for necessário ao trabalho de Laboratório (...) Um ano depois da abertura da aula de Química não se permitira exame de farmácia sem que preceda o de Química, sendo obrigados aos estudos da Química todos os que se destinarem à cirurgia medicina e ao ofício de boticário (...) Serão admitidos à Aula de Química todas as pessoas que quiserem instruir-se em tão importante ciência, seja qual for o seu destino ulterior (...) Ao lente porém será livre despedir da aula os que nâo se comportarem com a devida decência e subordinação.(...) (PM02 :65)

Estas instruções do Conde da Barca, escritas no ano de sua morte, aos 63 anos, quando a Química recém começava a ser reconhecida como uma ciência, são provavelmente as primeiras recomendações sobre o ensino de Química no Brasil.

É preciso ter presente que na Europa, principalmente na Alemanha, a Química Orgânica já estava iniciada e apresentava resultados práticos eficientes. (Chassot: 1995) É, paradoxalmente, o progresso que viria a ocorrer nesta área das sínteses orgânicas, especialmente no setor de corantes sintéticos, que representa uma das perdas econômicas do Bra- 
sil, que exportava madeiras, particularmente o pau-brasil, 7 também para extração de corantes.

Ainda das referidas instruções se pode verificar a simbiose entre a química e a mineralogia. Esta associação vai ser encontrada nas muitas propostas de modificações do ensino ainda durante todo o Império, o que traduz a prática no Brasil de então de uma Química, quase exclusivamente inorgânica, e por isso sua associação com a mineralogia (explicável pelas riquezas minerais do Brasil). Como já se referiu, e será mostrado adiante, no Império as preocupações do Conde da Barca, mais ligadas com uma Química aplicada e vinculada com a realidade, serão esquecidas com a migração para um ensino de Química livresco e fundamentalmente re-orientado para um humanismo retórico.

Assim dentre os três documentos antes referidos, coloco este terceiro documento como importante numa análise da constituição dos currículos de Química (do Brasil). Ao contemplarmos as Diretrizes para a cadeira de Química da Bahia do Conde da Barca é preciso recordar a criação de uma Cadeira de Química na Bahia, em Janeiro de 1817, quando uma carta do Rei reconhece a importância da Química para o progresso dos estudos da medicina, cirurgia e agricultura, e também é importante que se ensinem os princípios práticos da Química, e seus diferentes ramos e aplicados às artes e à farmácia para o perfeito conhecimento dos muitos e preciosos produtos, com que a natureza enriqueceu este reino do Brasil. Vemos que o Rei, multo provavelmente influenciado pelo seu $\mathrm{Mi}$ nistro ilustrado, Conde da Barca, tinha preocupações bem mais ampla que os professores de Coimbra, para definir o ensino da Química. Aliás isto já ficara evidenciado cinco anos antes da criação, na Corte, de um Laboratório químico-prático para o conhecimento das diversas substâncias que às artes, ao comércio e às indústrias nacionais podem subministrar os diferentes produtos dos três reinos da natureza extraídos dos domínios ultramarinos.

São, porém as instruções do Conde da Barca, como lá foi destacado que nos permitem fazer não só as melhores inferências sobre a situação do ensino de Química de então, mas encontrar as orientações que se gostaria ver imprimidas ao ensino, ainda hoje.

Vale destacar que esta inserção às coisas do cotidiano, diferente de uma postura apenas utilitarista para $o$ ensino, não encontramos no texto lavoisierano e muito menos nas diretrizes coimbrãs. $\mathrm{O}$ conde da Barca busca ligar o ensino da nova cadeira à economia do Brasil, de uma maneira muito realista pois diz que o professor explicará as dificuldades de construções dos fornos, tendo particular atenção ao trabalho das minas de ferro, e de outros metais que ainda abundam no reino do Brasil, para que possam ser utilmente aproveitados.

Se observa que há indicações de uma postura quase tutorial que deva ser assumida pelo professor, apesar de se achar estranhável que este trabalhe no período de férias. Talvez seja nas férias dos alunos, quando o professor estaria em atividades, orientando inclusive a coleta de materiais, para constituir o acervo da cadeira.

Pelo que se observa em várias outras recomendações curriculares posteriores, estas instruções do Conde da Barca, parecem ter morrido com o seu autor no mesmo ano que foram escritas, pois o que se encontra a seguir, principalmente com advento da Independência, 5 anos depois, é uma educação por demais elitista, com a migração para um ensino de Química livresco, teórico. apêndice da Física.

Parece que se pode afirmar que cada um dos três textos antes referidos foram representativos a sua maneira, para o ensino brasileiro:

- as recomendações coimbrãs, por serem aquelas que portavam a legitimidade (mesmo que sistematicamente claudicante) da Universidade portuguesa, foram as definidoras daquilo que seria o ensino no reino português no final do século XVIII e durante o século XIX e esta marca man- teve-se muito forte em todo o período do império brasileiro;

- o texto lavoisierano (e se inclua nele o Traité significante mundial da Química durante todo o século XIX, pelo prestígio científico da França) muito decisivo por ser obra de Lavoisier o livro texto das escolas militares brasileiras (e destas como vimos irradiadoras para as escolas de engenharia e daí para o ensino anterior a Universidade):

- e as recomendações do Conde da Barca, mesmo que consideradas elucubrações solitárias de um burocrata muito estudioso, servem para exemplificar como boas instruções podem ser letra morta, quando são ignoradas e para conferir a seu autor um pioneirismo na história da Educação Química no Brasil.

\section{NOTAS}

1 Parte deste texto foi apresentado, sob forma de uma comunicacão oral no V Seminário Nacional de Históría da Ciência e da Tecnologia, promovldo pela Socledade Brasileira de História da Ciência. realizada de 24 a 28 de julho de 1995. em Ouro Preto. MG

2 Uma das fontes que usei para a elaboração deste esboco histónco foi uma obra em 17 volumes de Primitivo Moacyr (1867-1942), que reuniu, em cerca de 7000 páginas o resultado de sua investigação em arquivos governamentais e em relatórios do governo documentos que são úteis à história da educação brasileira. É uma obra sem comentários (também sem uma contextualização), nem conclusôes, apenas uma volumosa coletănea de leis, projetos de leis, (muitas vezes repetitivos) e discussōes parlamentares. A seguir listo os 17 volumes, com as datas de suas publicações, antecedido da sigla que uso, quando dos mesmos extraio algum excerto. que então faço seguir da página onde inicia o texto que cito. A sigla PM, significa Primitivo Moacir, acompanhada do número de ordem de publicação dos referidos 17 volumes. PM-01 O Ensino no Congresso Nacional 1916.

PM 02 A Instrução e o Impéno $1^{\circ}$ volume (1823-1853, 616p: 1936.

PM 03 A Instrução e o Impéno $2^{\circ}$ volume (1850-1887) 614p: 1937

PM-04 A Instruç3c e o Impéno $3^{\circ}$ volume (1854-1889) 688p: 1938.

PM-05 A Instrução e as Provincias $l^{\circ}$ volume (Das Amazonas às Alagoas) 639p 1939.

PM $062^{\circ}$ volume (Sergipe. Bahia. Rio de Janeiro. São Paulo e Mato Grosso, 575p: 1939.

PM 07 A Instrução e as Províncias $3^{\circ}$ volume (Espirito Santo Minas Gerais. Santa Catari na Rio Grande do Sul e Goiás) 678p: 1940.

PM-08 A Instrução e a República $1^{\circ}$ volume (1890- 
1892) 269 p 1941.

PM-09 A Instrução e a República $2^{\circ}$ volume (18921899) 384 p 1941.

PM-10 A Instrução e a República $3^{\circ}$ volume (19001910) Zxt p 1941

PM-11 A Instrução e a República $4^{\circ}$ volume (1911 1925) zxt p 1942

PM-12 A Instrução e a República $5^{\circ}$ volume (1923. 1930) 236 p. 1942

PM-13 A Instrução e a República $6^{\circ}$ volume (Ensino Profissional) 194 p 1942.

PM-14 A Instrução e a República $7^{\circ}$ volume (Ensino Agronômico 1892 1929) 130 p 1942.

PM-15 A Instrução e a República $8^{\circ}$ volume (Universidades) zxt p 1941.

PM-16 A Instrução Pública em São Paulo $1^{\circ}$ volume 390p: 1942.

PM-17 A Instrução Pública em São Paulo $2^{\circ}$ volume 272p: 1942

Os volumes listados de 1 a 7 e 16 e 17 foram editados pela Companhia Editora Nacional, dentro de sua colecão Brasiliana e os outros oito foram editados pelo Instituto Nacional de Estudos Pedagógicos. pela Imprensa Nacional do Rio de Janeiro.

${ }^{3}$ A versão integral comentada do texto lavoisierano está em Lavoisier o pedagogo que é o Capítulo 2 de Chassot (1993).
${ }_{4}^{4}$ Aqui muito provavelmente, houve um erro de grafia. Ao invés de Faurevoy deve ser Fourcroy. A obra de Antoine Francois Fourcroy La Philosophie Chimique fol traduzida para o português e editada em Lisboa (1801) e reeditada no Rio de Janeiro (1816). Não é conhecido nem um autor com o nome mencionado. Provavelmen te o citado Vandequelin, deva ser Vanquelin.

5 Relativo à docimasia: Parte da química que procura determinar a proporção em que os metais entram nos minérios. Em Medicina Legal: Docimasia hepática. Dosagem de glicose e glicogênio no fígado, para distinguir a morte súbita da agônica.

Tendo em consideracões as muitas vantagens que devem resultar em benefício de meus vassalos, do conhecimento das diversas substâncias que às artes, ao comércio e às indústrias nacionais podem subministrar os diferentes produtos dos três reinos da natureza extraídos dos meus domínios ultramarinos, os quais não podem ser exata e adequadamente conhecidas e empregadas, sem se analisarem e fazerem necessárias tentativas concernentes às úteis aplicaçōes de que são suscetiveis: sou servido crear nesta Corte um Laboratório quíimico-prático, (PM-02:62).

${ }^{6}$ Ver nota 4

O pau-brasil (ibirapitanga, arabutã, orahutã, pau-de- pernambuco pau-pernambuco, pau-de-tinta pau-rosado, sapão) que deu o nome ao nosso país e uma árvore da familia das leguminosas (Caesalpinia echinata), e cuja madeira é vermelho-alaranjada e depois vermelhoviolácea pesada, dura e incorruptível. A árvore hoje rara, era intensamente procurada nos tempos coloniais, para a extração de um corante vermelho brasilina que depois de extraído oxida-se dando a brasileína que usase na Europa para tingir tecidos e fabricar tinta de escrever o pau-brasil era também usado para o fabrico de móveis e, especialmente de instrumentos musicais, como violinos.

\section{REFERÊNCIAS BIBLIOGRÁFICAS}

Chassot, Attico, Catalisando transformações na Educação. ljuí: Unijuí, 1993.

Chassot, Attico, A Ciêncioa através dos tempos, São Paulo: Moderna, 1994a.

Chassot, Attico, Para que(m) é útil o nosso ensino de Química? (Tese de doutorado). Porto Alegre: UFRGS. PPGEDU - 1994, 316 p. No prelo para publicação pela Editora da ULBRA.

Chassot, Attico, Alquimiando a Química. Química Nova na Escola 1, maio 19 (1995) 15

\title{
Biodinâmica
}

\section{Biónica Aplicada Lda.}

\author{
RUA DA GUINÉ, $2-2^{\circ} \mathrm{E}$ \\ 1100 LISBOA-PORTUGAL \\ TEL. 8150760 - FAX 8150770
}

\section{INSTRUMENTAÇÃO}

HI-TECH SCIENTIFIC - Stopped Flow e instrumentação para estudos de cinética de reacções rápidas.

PHOTON TECHNOLOGY INTERNATIONAL (PTI) - Fontes de Radiação, Fluorímetros (estado estacionário e de tempos de vida), Lasers de Azoto com ou sem laser de corantes, Fluorescência de Rácio, software.

IBH - Tempos de vida, Lâmpadas pulsadas, Detecção ultra rápida (fotomultiplicadores e instrumentação), software.

OLIS - Espectrofotómetros clássicos modernizados. Monocromadores de Scanning Rápido (até 1000 scans/sec)

CANBERRA INDUSTRIES - Instrumentação nuclear, detectores de estado sólido, etc.

BROOKHAVEN INSTRUMENTS - Analisadores de

tamanho de partículas por dispersão de luz, centrifugação e electrocinética.

KINETIC SYSTEMS - Mesas e "breadboards" para óptica.

GENTEC - Medidores de energia para lasers.

LASER SHIELD - Óculos de protecção para radiação laser (Nd-Yag, $\mathrm{CO}_{2}, \mathrm{He}-\mathrm{Ne}$ ), espectro largo e UV.

CORION - Gama completa de filtros ópticos.

STRAWBERRY TREE COMPUTERS - Placas e software para aquisição de dados.

HELLMA - Células (cuvettes) em vidro e quartzo.

Desenvolvimento e construção de instrumentação.

Exponha-nos as suas necessidades 


\section{Consegue cheirar}

a diferença?

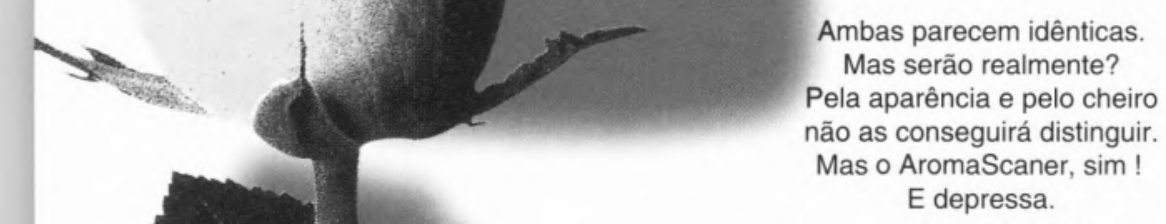

\section{AromaScan, Sim!}

Desde a selecção de matérias primas e desenvolvimento de novos produtos até

ao contrôlo de fabrico "on-line"

e contrôlo de qualidade do produto final, a tecnologia única da AromaScan, ajudá-lo-á a classificar, identificar, discriminar entre aromas simples ou complexos.

AromaScan provou o seu valor em laboratórios de cosmética, e linhas de processo

à volta do mundo, reduzindo percas,

optimizando a produtividade e ajudando o contrôlo de qualidade.

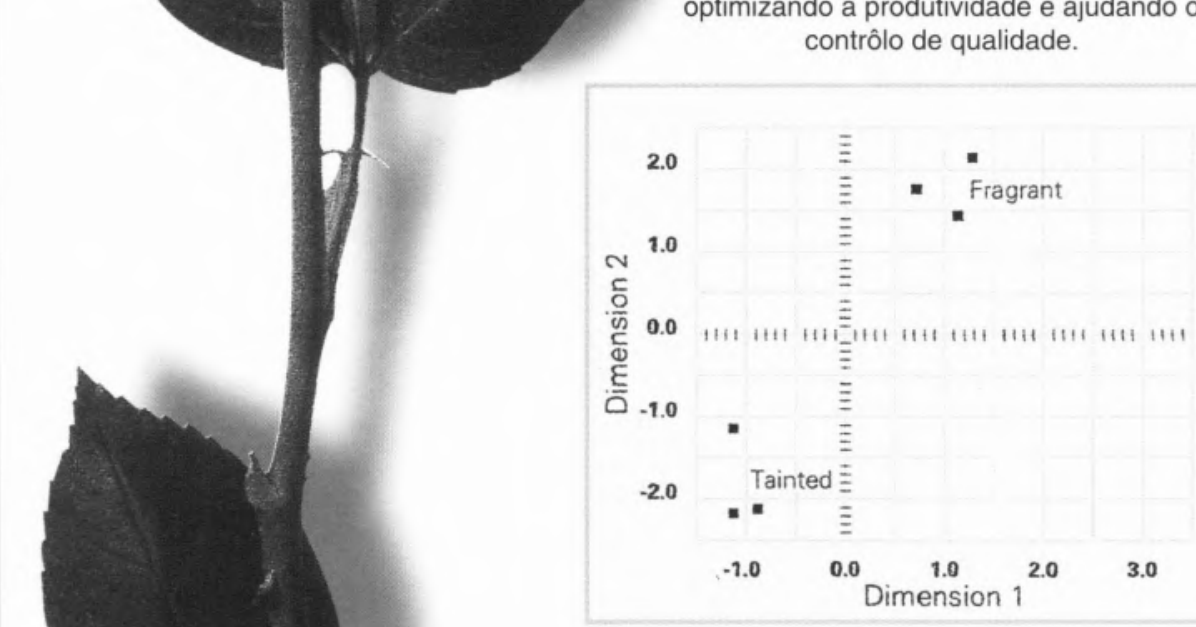

Gráfico AromaScan a 2 dimensões a partir de informação multidimensional de aromas, permite tomar decisões de forma rápida e simples.

Como lider mundial no desenho, desenvolvimento e fabricação de sistemas sensoriais que copiam o nariz humano, AromaScan poderá ajudá-lo a reconhecer a diferença.

Deixe que the provemos.

Contacte já o distribuidor exclusivo em Portugal:
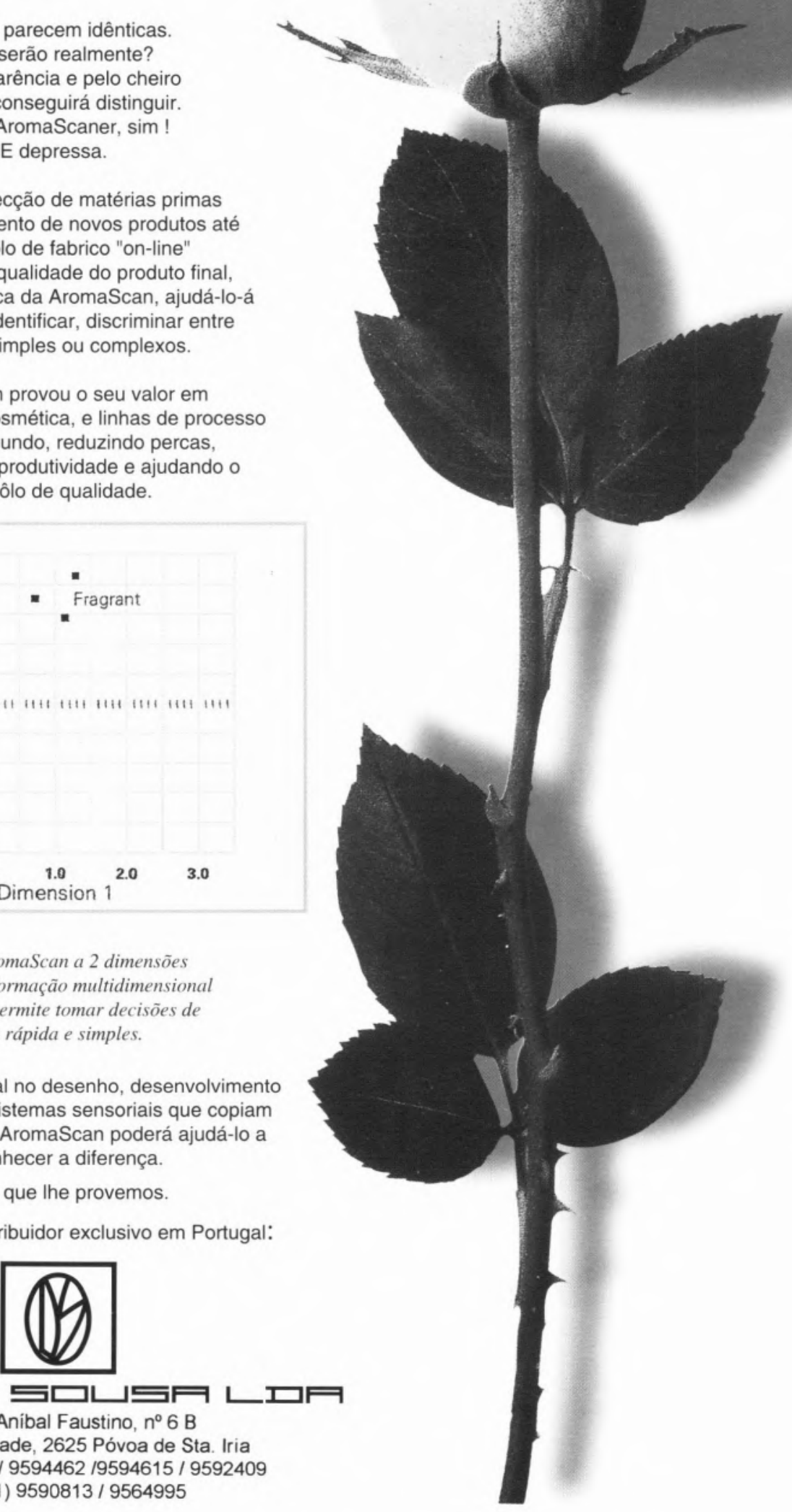